\title{
Specific wushu sanda high-intensity interval training protocol improved physical fitness of amateur athletes': A pilot study
}

\author{
Jorge Rafael Farias MONTEIRO ${ }^{1}$ (D), Fabrício Boscolo del VECCHIO² (D), Breno Berny \\ VASCONCELOS 2 (D) \& Victor Silveira COSWIG ${ }^{*}$ \\ ${ }^{1}$ Faculty of Physical Education, Federal University of Pará, Belém (Brazil) \\ ${ }^{2}$ High School of Physical Education, Federal University of Pelotas, Pelotas (Brazil) \\ ${ }^{3}$ Faculty of Physical Education, Federal university of Pará, Castanhal (Brazil)
}

Received: 07/10/2019; Accepted: 18/01/2020; Published: 20/01/2020.

\begin{abstract}
Objective: To investigate the effects of the addition of a specific high-intensity intermittent training (HIIT) protocol to the habitual training on the physical fitness of amateur wushu sanda athletes. Methods: This is an experimental study in which 6 amateur regional level wushu sanda athletes $(24.6 \pm 6.4 \mathrm{yrs}, 1.70 \pm 0.1 \mathrm{~m}$ height, and $71.3 \pm 7.3 \mathrm{~kg}$ weight $)$ underwent a 2 session/week training program for 4 weeks. The HIIT specific protocol was composed of 3 rounds of 2 minutes with 1-minute intervals in between, simulating a match duration. Each round was divided into 8 blocks of 15 seconds. Each block was composed of 5 seconds of high-intensity activities, 5 seconds of low-intensity activities and 5 seconds of pause. Countermovement jump, squat jump, horizontal jump, aerobic fitness (TKDtest) and kick speed test (FSOK) were applied. Results: Athletes presented performance increases in countermovement jump (from $41 \pm 5.7$ to $47.3 \pm 7.3 \mathrm{~cm}, p=0.007$, $g=0.88$ ), horizontal jump (from $1.7 \pm 0.4$ to $2.3 \pm 0.3 \mathrm{~cm}, p=0.01, g=1.56$ ) and in the FSOK test (from $19.8 \pm 1.7$ to $23.0 \pm 2.5$ kicks, $p=0.003, g=1.38$ ). The resting heart rate decreased (from $120 \pm 8.3$ to $107 \pm 11.4 \mathrm{bpm}, p=0.03, g=1.20$ ) and the time to exhaustion increased (from $8.5 \pm 1.8$ to $13.1 \pm 1.4 \mathrm{~min}, p=0.003, g=2.63$ ), as well as the number of kicks (from $187 \pm 55.3$ to $368 \pm 39.8$ kicks, $p=0.001, g=3.46$ ). Conclusion: Despite the small sample size, the large effect sizes found support the conclusion that the addition of a specific HIT wushu sanda protocol to amateur athletes' training routine can lead to neuromuscular, aerobic and anaerobic performance improvements.

Keywords: Martial arts; combat sports; wushu; high-intensity interval training; physical conditioning.
\end{abstract}

\section{Un protocolo específico de entrenamiento interválico de alta intensidad de wushu sanda mejora la condición física de atletas amateur: un estudio piloto}

\section{Resumen}

Objetivo: Investigar los efectos de añadir un protocolo específico de entrenamiento interválico de alta intensidad (HIIT) al entrenamiento habitual de condición física de atletas amateur de wushu sanda. Métodos: Estudio experimental, en el que 6 atletas amateur de wushu sanda de nivel regional $(24.6 \pm 6.4$ años, $1.70 \pm 0.1 \mathrm{~m}$ de altura y $71.3 \pm 7.3 \mathrm{~kg}$ de peso) se sometieron a un programa de entrenamiento de 2 sesiones/semana durante 4 semanas. El protocolo de HIIT estuvo compuesto de 3 rondas de 2 minutos con intervalos de 1 minuto entre ellas, simulando la duración de un combate. Cada ronda se dividió en 8 bloques de 15 segundos. Cada bloque estaba compuesto de 5 segundos de actividades de alta intensidad, 5 segundos de actividades de baja intensidad y 5 segundos de pausa. Se utilizaron saltos con contramovimiento, sentadillas, saltos horizontales, test de aptitud aeróbica (TKDtest) y test de velocidad de patada (FSOK). Resultados: Los atletas presentaron aumentos de rendimiento en salto con contramovimiento (de $41 \pm 5.7$ a $47.3 \pm 7.3 \mathrm{~cm}, p=0.007$, $g=0.88$ ), salto horizontal (de $1.7 \pm 0.4$ a $2.3 \pm 0.3 \mathrm{~cm}, p=0.01$,
Protocolo específico de treinamento intervalado de alta intensidade do wushu sanda melhorou a aptidão física de atletas amadores: um estudo piloto

\section{Resumo}

Objetivo: Investigar os efeitos da adição de um protocolo específico de treinamento intermitente de alta intensidade (HIIT) ao treinamento habitual de wushu sanda na aptidão física de atletas amadores. Métodos: Estudo experimental em que 6 atletas amadores de nível regional de wushu sanda $(24,6 \pm 6,4$ anos, $1,70 \pm 0,1$ m de estatura e $71,3 \pm 7,3$ $\mathrm{kg}$ de massa corporal) foram submetidos a um programa de treinamento de 2 sessões/semana por 4 semanas. 0 protocolo HIIT foi composto por 3 rounds de 2 minutos, com intervalos de 1 minuto, simulando a duração da luta. Cada round foi dividido em 8 blocos de 15 segundos. Cada bloco foi composto por 5 segundos de atividades de alta intensidade, 5 segundos de atividades de baixa intensidade e 5 segundos de pausa. Foram aplicados saltos com contramovimento, salto em agachamento, salto horizontal, teste de aptidão aeróbia (TKDtest) e teste de velocidade de chute (FSOK). Resultados: Os atletas apresentaram aumentos de desempenho no salto com contramovimento (de $41 \pm 5,7$ para $47,3 \pm 7,3 \mathrm{~cm}, p=0,007$, $g=0,88$ ), salto horizontal (de $1,7 \pm 0,4$ para $2,3 \pm 0,3 \mathrm{~cm}$,

*E-mail: vcoswig@gmail.com 
$g=1.56$ ) y en la prueba FSOK (de $19.8 \pm 1.7$ a $23.0 \pm 2.5$ patadas, $p=0.003, g=1.38$ ). La frecuencia cardíaca en reposo disminuyó (de $120 \pm 8.3$ a $107 \pm 11.4 \mathrm{lpm}, p=0.03$, $g=1.20$ ) y el tiempo hasta el agotamiento aumentó (de $8.5 \pm 1.8$ a $13.1 \pm 1.4 \mathrm{~min}, p=0.003, g=2.63$ ), así como el número de patadas (de $187 \pm 55.3$ a $368 \pm 39.8$ patadas, $p=0.001, g=3.46)$. Conclusión: A pesar del pequeño tamaño de la muestra, los grandes tamaños de efectos hallados respaldan la conclusión de que añadir un protocolo HIIT específico de wushu sanda a la rutina de entrenamiento de atletas amateur puede producir mejoras en el rendimiento neuromuscular, aeróbico y anaeróbico.

Palabras clave: Artes marciales; deportes de combate; wushu, entrenamiento interválico de alta intensidad; acondicionamiento físico. $p=0,01, p=1,56$ ) e no teste FSOK (de $19,8 \pm 1,7$ a $23,0 \pm 2,5$ chutes, $p=0,003, p=1,38)$. A frequência cardíaca em repouso diminuiu (de $120 \pm 8,3$ para $107 \pm 11,4 \mathrm{bpm}$, $p=0,03, p=1,20$ ) e o tempo para exaustão aumentou (de $8,5 \pm 1,8$ para $13,1 \pm 1,4 \mathrm{~min}, p=0,003, p=2,63$ ), bem como no número de chutes (de $187 \pm 55,3$ a $368 \pm 39,8$ chutes, $p=0,001, p=3,46)$. Conclusão: Apesar do pequeno tamanho da amostra, os grandes tamanhos de efeito encontrados permitem sugerir que a adição de um protocolo específico de HIIT para wushu sanda à rotina de treinamento de atletas amadores pode levar a melhorias no desempenho neuromuscular, aeróbio e anaeróbio.

Palavras-chave: Artes Marciais; esportes de combate; wushu; treinamento intervalado de alta intensidade; condicionamento físico.

\section{Introduction}

Sanda is a combat sport developed from wushu (also called Kung Fu), a set of Chinese martial arts. It was developed in 1960 for competitive purposes with specific rules and equipment (Vasconcelos \& Del Vecchio, 2017). The matches last until 3 rounds of 2 min each with 1-min intervals in between and occur in a squared elevated platform (leitai) $80 \mathrm{~cm}$ high and $800 \mathrm{~cm}$ long and wide, coated with shock-absorbing materials (Theeboom, Zhu, \& Vertonghen, 2017). Athletes use motor actions such as punches, kicks, and throws, demanding speed, precision, and power, which are considered unimpeachable physical capacities for competitive success in this modality (Deng, 2017; Theeboom et al., 2017; Vasconcelos \& Del Vecchio, 2017). Regarding technical aspects and specific motor characteristics, wushu sanda is classified as a mixed-orientation combat sport, with striking (punches and kicks) and grappling (throwing) actions (Del Vecchio, Silva, \& Farias, 2015; Silva, Del Vecchio, Picanço, Takito, \& Franchini, 2011).

Like other combat sports, sanda is an acyclic intermittent modality composed of blocks of short duration and high-intensity efforts, leading to a high aerobic contribution (Del Vecchio, Coswig, \& Neves, 2012). Studies on the temporal structure of combat sports showed the relevance of interval training in athletes' physical preparation, since this training strategy attends these sports' specificities while simulating real competitive situations (Del Vecchio, Hirata, \& Franchini, 2011). A recent systematic review tested the effects of high-intensity interval training (HIIT) on Olympic combat sports' athlete's performance and most of them employing general and unspecific exercises such as running, rowing and cycling (Franchini, Cormack, \& Takito, 2019). Indeed, ome of these findings showed relevant improvements in athletes' physical performance in both grappling (Farzad et al., 2011) and striking (Ravier, Dugué, Grappe, \& Rouillon, 2009) modalities.

Notwithstanding, some studies tried to structure HIIT protocols based on combat sports' specific characteristics and their technical-tactical and time-motion structure (Franchini et al., 2017). This kind of protocol can be designed considering the effort:pause ratio (E:P), the high to low-intensity ratio (HI:LI) and specific motor actions of the modality (Del Vecchio et al., 2011). For example, Andreato et al. (2013) suggested a training program for Brazilian jiu-jitsu (BJJ) where 3-5s high-intensity specific efforts should be interspersed by 20-25 of low-intensity actions, which respect the 1:6 HI:LI ratio of the modality. Another example was suggested by Del Vecchio et al. (2011) for mixed martial arts (MMA) athletes. In this sense, unpublished data from our lab showed that the E:P of 2.4:1 and a HI:LI of 1:1.6 was found from 245 rounds of 145 matches from the $13^{\text {th }}$ World Wushu Championships. Thus, it is suggested that specific training programs should be designed based on that information.

However, up to date and to the author's knowledge, wushu training programs are usually settled based on tradition, intuition and coaches' previous experiences, just like many other martial arts and combat sports (Artioli et al., 2009) and effects of specific protocols are not known. Thus, a deeper understanding of the modality's technical and tactical aspects is required to enhance specific training prescriptions, which may increase athletes' competitive performance. Also, specific HIIT protocols have been successfully applied to combat sports athlete's routines and may are superior to unspecific protocols (cycling, running, rowing, etc.) to enhance their performance 
(Ribeiro et al., 2015). However, studies on this subject in wushu sanda athletes are lacking. Therefore, this study aimed to investigate the effects of the addition of a specific HIIT protocol to the habitual training on the physical fitness of amateur regional level wushu sanda athletes. We hypothesize that relevant improvements in physical fitness can be achieved when specific HIIT protocols are added to habitual wushu sanda training.

\section{Methods}

\subsection{Study type and sample}

This is an experimental study approved by the local ethical committee (CAAE: 16607019.8.0000.0018) and all subjects signed the informed consent form. To be part of the sample, athletes should practice wushu sanda for at least 1 year, train at least 3 times per week and fit on the weight categories light $(-60 \mathrm{~kg})$, middle $(-75 \mathrm{~kg})$ or heavy $(+75 \mathrm{~kg})$ (Chang, 2013). Also, athletes should not present any restrictions that prevent or limit the execution of any of this study's procedures, as recent injuries or illness. Those who did not complete all of the evaluations or had a frequency of less than $75 \%$ in the training sessions were excluded. A total of 16 regional level athletes were invited to take part in the study, from those 8 were excluded for not reaching $75 \%$ of frequency in the training program and 2 left the study for personal reasons. Therefore, this study's sample was composed of 6 male athletes (24.6 $\pm 6.4 \mathrm{yrs}, 1.70 \pm 0.1 \mathrm{~m}$ height, and $71.3 \pm 7.3 \mathrm{~kg}$ weight), who underwent a 4-weeks training program.

\subsection{High-intensity interval training protocol (HIIT)}

The specific HIIT protocol was based on sanda E:P and HI:LI ratios based on unpublished data from our laboratory, which comprises the same project than a published work with female athletes (Vasconcelos \& Del Vecchio, 2017). For convenience and to easily control the training prescription, values of E:P were rounded to $2: 1$ and the $\mathrm{H}: \mathrm{L}$ was considered 1:1. The protocol was composed of 3 rounds of 2 min with 1-min intervals in between, simulating a match duration. Athletes performed a pre-established set of motor actions (punches, kicks, and throws) in another athlete, which was holding a kicking/punching pad. The motor actions were defined according to a previous study that characterized the most common and successful motor actions in wushu sanda matches (Yin, 2010). Each 1-min round was divided into 8 blocks of 15s. Each block was composed of $5 \mathrm{~s}$ of high-intensity activities, $5 \mathrm{~s}$ of low-intensity activities and $5 \mathrm{~s}$ of pause. The high-intensity intervals were composed of punches and kicks on the first round, only kicks on the second round and punches, kicks and throws simulations on the third round. The types of punches, kicks, or throws were freely selected by each fighter. The low-intensity intervals were composed of linear and slow stepping movements at a free pace. The pause intervals were composed of passive recovery. Along with all the protocol execution, athletes had verbal encouragement and intervals were controlled by predefined chronometer.

\subsection{Procedures}

In the first meeting, the subjects arrived in the afternoon to the lab, at their usual training hour and were informed of the study's objectives, then read and signed the written informed consent form. After that, athletes performed a 10-min standardized warm-up composed by jogging, calisthenics and specific actions of the modality. Physical fitness was evaluated using the tests of countermovement jump, squat jump, horizontal jump, kick speed (FSOK) and aerobic fitness (TKDtest), in that order. Subjects were asked to be rested, hydrated, fed at least 2 hours before the tests, not to engage in physical activities for at least 24 hours, not to ingest any substance that could potentially affect their heart rate and by dressing in their usual workout uniform. Firstly, subjects were familiarized with the tests and then performed each one. After that, subjects underwent a 4weeks training program composed of 8 sessions 2 times per week. Before each session, subjects performed a 5-min warm-up using exercises they were used to perform during their training routine, such as jumping jacks, running and jump rope. After a 2 min recovery, athletes were organized in pairs, in which one of them would hold the punching/kicking pad and the other one was going to execute the HIIT protocol. When the first athlete concluded his HIIT protocol, the roles were exchanged after 5-min of recovery. This time of recovery was arbitrarily chosen based on 
training logistics and to provide enough time to hydration and equipment (pads and gloves) change. After the conclusion of the 4-weeks training program, the physical tests were applied again.

\subsection{Data collection}

The countermovement jump and the squat jump were performed as previously recommended (Salles, Vasconcellos, de Salles, Fonseca, \& Dantas, 2012). Briefly, subjects had their fingers on the right hand marked with chalk, while standing flat-footed next to a wall on their right side, and right arm extended above the head, the subjects marked on the wall the highest point they could reach. After that, they performed the countermovement jump. At the highest point of the jump, they should extend the right hand against the wall as to mark the maximum height jumped. The jump height was the difference between the two points marked on the wall. All subjects jumped three times, with a minimum interval of $45 \mathrm{~s}$ between the jumps and only the highest jump was considered. The same protocol was followed for the squat jump, except for the starting position, which was squatted ( $\sim 90^{\circ}$ knee flexion).

For the horizontal jump subjects started from a standing position (Bulten, King-Dowling, \& Cairney, 2019). They commenced the jumps by swinging their arms and beginning their knees to provide maximal forward drive. A take-off mark was drawn on the floor. The jump-length measurement was determined using the distance from the take-off mark to the nearest point of landing contact. All subjects jumped three times, with a minimum interval of $45 \mathrm{~s}$ between the jumps and only the highest jump was considered.

The aerobic fitness was measured thought maximal oxygen uptake estimation and heart rate monitoring using the cardiopulmonary exercise test TKDtest, a specific incremental protocol for taekwondo athletes (Araujo et al., 2015). The TKDtest consists of 1-min stages of kicks with an incremental load between them. The subjects performed kicks each time a sound signal was heard. The first stage contained a 10 beats load, and 3 beats were added per minute. The test was considered maximal when athletes gave up due to fatigue or when at least 3 kicks were missed. The original protocol utilizes the dolio-tchagui kick (roundhouse kick), one of the most utilized kicks in taekwondo. Athletes utilized the héng băi tī tuǐ with their preferred leg, a roundhouse kick very similar to taekwondo's kick. The roundhouse kick was shown to be the most utilized kick in wushu sanda competitions (Chang, 2013; Yin, 2010). During the protocol, heart rate was monitored continuously, and the number of kicks and total time were measured. Heart rate was measured using a heart rate monitor (Speedo, model 58010G0EVNP1) held by the evaluator and the kicks' frequency using a smartphone app (Metronome Beats, 4.1.2, Stonekick) that simulates a metronome (Araujo et al., 2015).

The kick speed was measured through the Frequency Speed of Kick Test (FSOK), a previously validated test in different combat sports (da Silva Santos \& Franchini, 2016). Subjects were asked to perform the highest number they could of sanda's roundhouse kicks in a punching bag. They should use their dominant leg and kicks should be performed at least at the ribs' level. The maximum number of kicks performed in a 10s interval was registered.

\subsection{Statistical analysis}

Data distribution and homogeneity was attested using the Shapiro Wilk's and Levene's test, respectively. Descriptive statistics were performed, and variables were presented in means and standard deviations. For inferential statistics, a Paired Student's T-test was applied considering the pre and post-training program periods. Effect size according to Hedge's $g$ was presented, classified as trivial (0.25), small $(0.25-0.50)$, moderate $(0.50-1.00)$ and large $(>1.00)$. Analysis was performed using the statistical package SPSS 20.0. The level of significance adopted to all tests was $p<0.05$.

\section{Results}

Physical performance outcomes are presented in Table 1, while individual and mean percentage change values are presented in Figure 1. The performance on countermovement jump and horizontal jump increased significantly with moderate and large effect sizes, respectively. The number of kicks in 10s increased significantly with a large effect size. Between the progressive 
test's variables, the heart rate in rest decreased and the total of kicks and the final stage increased significantly, all with large effect sizes. One of the subjects did not present any changes while the other one presented a decrease in squat jump performance. For the heart rate in rest, only one subject presented an increase. All other subjects presented positive adaptations to the training program. The heart rate outcomes are present in Figure 2. It can be noticed that, in general, heart rate presented lower values at baseline, however, significant changes were identified only in stages $6(\mathrm{t}=2.8 ; p=0.03 ; g=1.52)$ and $7(\mathrm{t}=3.04 ; \mathrm{p}=0.03 ; g=1.89)$, both with large effects. It is possible to notice that, meanly, subjects sustained four extra stages until exhaustion after the training program.

Table 1. Physical performance outcomes to a 4-weeks program using a specific highintensity interval wushu sanda training protocol $(n=6)$.

\begin{tabular}{lccccc}
\hline \multicolumn{1}{c}{ Variables } & Pre & Post & t & $\boldsymbol{p}$ & $\boldsymbol{g}$ \\
\hline Countermovement jump (cm) & $41.0 \pm 5.7$ & $47.3 \pm 7.3$ & -4.42 & 0.007 & 0.88 \\
Squat jump (cm) & $42.7 \pm 6.0$ & $44.8 \pm 5.9$ & -1.18 & 0.288 & 0.32 \\
Horizontal jump (m) & $1.7 \pm 0.4$ & $2.3 \pm 0.3$ & -3.56 & 0.016 & 1.56 \\
FSOK (n) & $19.8 \pm 1.7$ & $23.0 \pm 2.5$ & -5.27 & 0.003 & 1.38 \\
Incremental test & & & & & \\
HR rest (bpm) & $120 \pm 8.3$ & $107 \pm 11.4$ & 2.87 & 0.035 & 1.20 \\
HR mean (bpm) & $176 \pm 6.8$ & $172.9 \pm 9.1$ & 1.26 & 0.263 & 0.35 \\
HR max (bpm) & $188 \pm 3.9$ & $187 \pm 7.4$ & 0.25 & 0.806 & 0.15 \\
Total kicks delivered (n) & $187 \pm 55.3$ & $368 \pm 39.8$ & -8.26 & 0.001 & 3.46 \\
Final stage (n) & $8.5 \pm 1.8$ & $13.1 \pm 1.4$ & -5.53 & 0.003 & 2.63 \\
\hline
\end{tabular}

HR= Heart rate; $g=$ Effect size by Hedges's $g$; FSOK: Frequency Speed of Kick Test

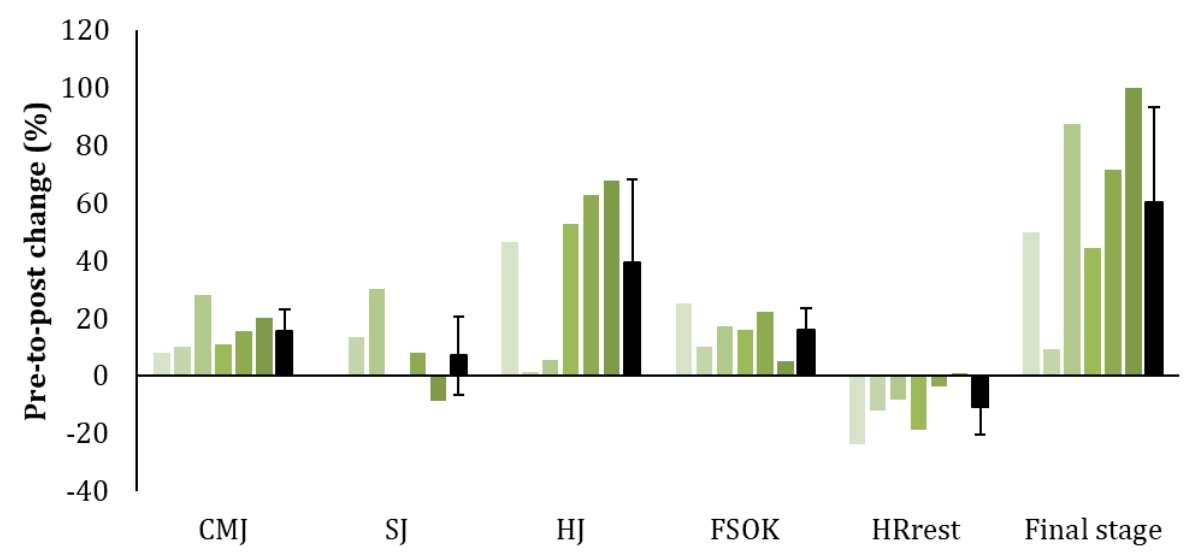

Gray bars represent each subject and dark bars represent the mean and standard deviations. CMJ: Countermovement Jump; SJ: Squat Jump; HJ: Horizontal Jump; FSOK: Frequency Speed of Kicks; HRrest: Resting heart rate.

Figure 1. Individual and mean percentage chance in physical performance pre and post a 4-weeks program using a specific high-intensity interval wushu sanda training protocol $(n=6)$.

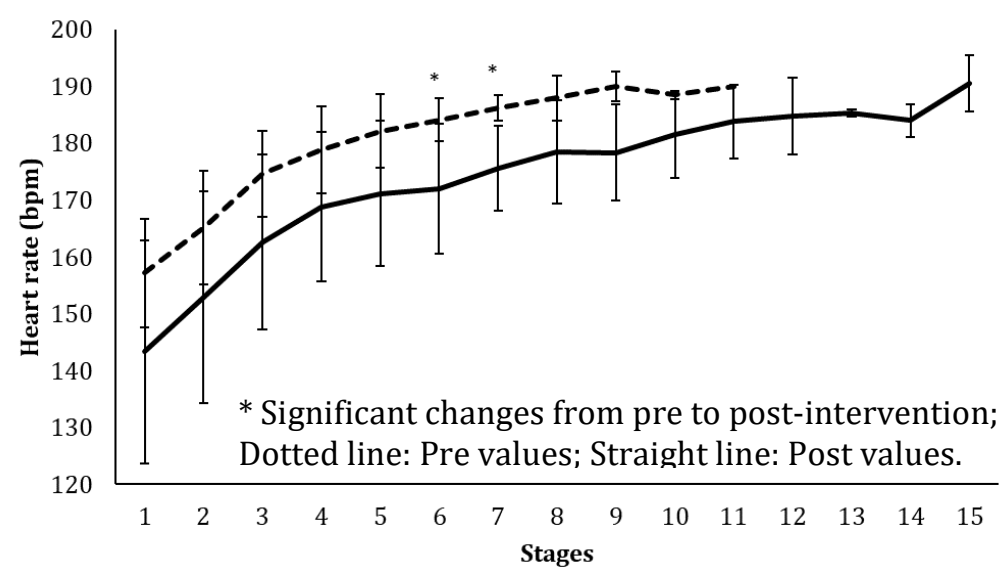

Figure 2. Heart rate outcomes in a progressive kicking test pre and post a 4-weeks program using a specific high-intensity interval wushu sanda training protocol $(n=6)$. 


\section{Discussion}

The present study aimed to test a new specific HIIT wushu sanda protocol and its effects on athletes' physical capacities, looking for enhancing their physical performance. The main findings were that adding 2 sessions per week for 4 weeks of this specific protocol to athletes' training routine led to significant improvements in aerobic capacity, lower limbs' muscle power and kicks speed in amateur regional level wushu sanda athletes. Considering that sanda is a combat sport with high aerobic demands in which athletes need to have high anaerobic power in both upper and lower limbs (Yoshida \& Ribeiro, 2016), the protocol proposed here showed to be of interest for enhancing these desirable capacities since these variables are determinant for competitive success.

These study's findings suggested that the training program induced a relevant improvement in subjects' neuromuscular function. Athletes' lower limb power significantly increased on the countermovement jump test, squat jump test and horizontal jump test, and anaerobic power on frequency speed of kick test. There was also a relevant improvement in aerobic capacity since for the progressive test, the resting heart rate decreased and the time until exhaustion increased. These findings may be explained by HIIT's properties, which are efficient in aerobic energy utilization in which the maximum aerobic capacity can be greater than $100 \%$ and the passive recovery is around 55\% (Buchheit \& Laursen, 2013).

The effects of HIIT protocols in combat sports athletes were previously tested in different modalities, using general protocols (running, rowing or cycling) and specific task protocols. The effects of adding HIIT sessions to international level karate athletes' habitual routine was previously tested (Ravier et al., 2009). The protocol involved 7 to 920 s running bouts at $140 \%$ of $\mathrm{vVO}_{2 \max }$ in a treadmill, interspersed by 15s interval between bouts. The intervention group presented impressive physiological adaptations in a progressive treadmill test, where athletes had their time to exhaustion increased $23.6 \%$ and maximal oxygen uptake increased by $4.6 \%$. Also, peak blood lactate and post-test concentrations increased by $12.9 \%$ and $53.2 \%$. In a similar design, 2 sessions/week of sprint interval training ( 6 all-out bouts of 35 min with 10s rests between bouts and $3 \mathrm{~min}$ rest between sets. 1 set was added per week) were added to the training program of national-level wrestlers for 4 weeks (Farzad et al., 2011). In a progressive treadmill test, athletes had their time to exhaustion increased $32.2 \%$ and maximal oxygen uptake in $5.4 \%$. In 4 successive lower limbs Wingate tests, athletes had their peak and mean power output increased by $19.1 \%$ and $6.3 \%$ in the first sprint and by $36.7 \%$ and $9.1 \%$ in the second. Taken together, these findings suggest that, even with general and unspecific protocols, positive outcomes can be expected when HIIT is added to combat sports training.

On the other hand, specific modality tasks' protocols were also tested. Ribeiro et al. (2015) added 3 sessions/week of a specific protocol based on BJJ motor gestures to the habitual training routine. For 10 weeks, a specific technique (a different technique per week) was performed for 1min in maximum effort with 1-min rests between efforts. Findings suggested that maximal oxygen uptake increased $16.33 \%$ and specific endurance and specific speed increased $18.9 \%$ and $20.7 \%$ respectively. Also, vertical jumping increased by $24.16 \%$. However, despite specific motor gestures were applied, the time-motion structure was not respected. A study by Franchini et al. (2013) considered the time-motion structure of judo and proposed a protocol composed of two blocks of 10 sets of 20 s of all-out effort interspersed by 10 s intervals. The authors compared cycling HIIT for upper and lower limbs against a specific HIIT protocol (uchi-komi). The main findings suggested that after 4-weeks of training twice a week, the uchi-komi group increased both lower (16.7\%) and upper limb peak power (8.5\%). Here, wushu sanda athletes' countermovement jump performance increased $15.4 \%$ and horizontal jump performance increased $35.3 \%$.

Regarding HIIT training for striking-type combat sports, Kamandulis et al. (2018) a simulated fight composed by three rounds ( 14 sets of 3 s all-out punching with 10 s rest) against a punching bag. After 4-weeks of training thrice a week upper-body aerobic power and punching abilities were improved in amateur boxers. Thereupon, HIIT can induce important changes in the aerobic and anaerobic performance of combat sports athletes, as suggested in a recent review (Franchini et al., 2019). Finally, our results seem to contribute to the body of knowledge about the effects of HIIT specific protocols to improve the physical performance of fighters with low training volumes. It is of interest to coaches, trainers and athletes since the reduction of training load can 
reduce the risk for non-functional overreaching, overtraining and, thus, risk of injury. Therefore, studies exploring the potential of HIIT programs among combat sports athletes are quite relevant, especially with specific time-motion and technical-tactical based protocols, since aerobic and anaerobic performance are fundamental for competitive success.

Finally, some limitations should be considered while interpreting our findings. First, the small sample size could reduce statistical power, however, to minimize we presented individual data. Also, small sample sizes are frequent in combat sports research due to sample specificity and efforts to maintain homogeneity. Also, even with this small sample size, large effect sizes were found. Second, a control group would be of interest, especially for comparisons between different training protocols, however, we believe that our findings are still relevant as a descriptive/pilot study, mainly due to its novelty and originality. Third, the low internal validity of these tests applied needs to be considered as a limitation, however, we believe that it is a strength as well, since these field tests can be easily implemented in trainers, coaches and athletes' routines.

\section{Conclusion}

Despite the small number of subjects in our sample, the large effect sizes found here allow us to conclude that the addition of a specific HIIT wushu sanda protocol to amateur athletes' training routine leads to neuromuscular, aerobic and anaerobic performance improvements. With this limitation in mind, this pilot study may serve as a significant reference for further studies on the topic. Specifically, athletes presented performance improvements in the countermovement jump, horizontal jump and in the frequency speed of kicks test. Regarding the incremental test, the resting heart rate decreased and the time to exhaustion increased, as well as the number of kicks. Together, our findings suggest that this HIIT protocol can induce improvements in physical fitness while maintaining high training specificity.

\section{References}

Andreato, L. V., Franchini, E., De Moraes, S. M. F., Pastório, J. J., da Silva, D. F., Esteves, J. V. D. C., ... Machado, F. A. (2013). Physiological and technical-tactical analysis in brazilian jiu-jitsu competition. Asian Journal of Sports Medicine. doi: 10.5812/asjsm.34496

Araujo, M., Nobrega, A., Espinosa, G., Hausen, M., Castro, R., Soares, P., \& Gurgel, J. (2015). Proposal of a new specific cardiopulmonary exercise test for taekwondo athletes. Journal of Strength and Conditioning Research, 31(6), 1525-1535. doi: 10.1519/JSC.0000000000001312

Artioli, G. G., Gualano, B., Franchini, E., Batista, R. N., Polacow, V. O., \& Lancha, A. H. (2009). Physiological, performance, and nutritional profile of the brazilian olympic wushu (kung-fu) team. Journal of Strength and Conditioning Research. doi: 10.1519/ISC.0b013e318187687a

Buchheit, M., \& Laursen, P. B. (2013). High-intensity interval training, solutions to the programming puzzle: Part II: Anaerobic energy, neuromuscular load and practical applications. Sports Medicine, 43(10), 927-954. doi: 10.1007/s40279-013-0066-5

Bulten, R., King-Dowling, S., \& Cairney, J. (2019). Assessing the Validity of Standing Long Jump to Predict Muscle Power in Children With and Without Motor Delays. Pediatric Exercise Science, 1-6. doi: $10.1123 /$ pes.2018-0277

Chang, B. (2013). On women Sanda athletes using wrestling techniques in 2012 Shanxi Wushu Championships. Wushu Science, 10(4), 59-61.

da Silva Santos, J. F., \& Franchini, E. (2016). Is frequency speed of kick test responsive to training? A study with taekwondo athletes. Sport Sciences for Health. doi: 10.1007/s11332-016-0300-2

Del Vecchio, F. B., Hirata, S. M., \& Franchini, E. (2011). A Review of Time-Motion Analysis and Combat Development in Mixed Martial Arts Matches at Regional Level Tournaments. Perceptual and Motor Skills, 112(2), 639-648. doi: 10.2466/05.25.PMS.112.2.639-648

Del Vecchio, F. B., Silva, J. J. R., \& Farias, C. B. (2015). Análise temporal de combates de Muay-Thai de nível nacional: Efeitos da fase competitiva. Revista de Artes Marciales Asiáticas, 10(1), 34-41. doi: $10.18002 /$ rama.v10i1.1635

Del Vecchio, F., Coswig, V., \& Neves, A. (2012). Modalidades esportivas de combate de domínio: respostas bioquímicas, hematológicas e hormonais. Revista Brasileira de Fisiologia do Exercício, 11, 246-254. doi: http://dx.doi.org/10.33233/rbfe.v11i4.3413 
Deng, L. (2017). Measurement of surface electromyography characteristics of Wushu athletes in the technical movement based on telemetry EMG. Acta Technica CSAV (Ceskoslovensk Akademie Ved), 62(3A), 127-134.

Farzad, B., Gharakhanlou, R., Agha-Alinejad, H., Curby, D. G., Bayati, M., Bahraminejad, M., \& Mäestu, J. (2011). Physiological and performance changes from the addition of a sprint interval program to wrestling training. Journal of Strenght and Conditioning Research, 25(9), 23922399. doi: $10.1519 /$ ISC.0b013e3181fb4a33

Franchini, E., Cormack, S., \& Takito, M. Y. (2019). Effects of High-Intensity Interval Training on Olympic Combat Sports Athletes' Performance and Physiological Adaptation: A Systematic Review. Journal of Strength and Conditioning Research, 33(1), 242-252 doi: 10.1519/ISC.0000000000002957

Franchini, E., Julio, U. F., Gonçalves Panissa, V. L., Lira, F. S., Agostinho, M. F., \& Branco, B. H. M. (2017). Short-term low-volume high-intensity intermittent training improves judo-specific performance. Journal of Science and Medicine in Sport, 20 (s1), e116. doi: 10.1016/j.jsams.2017.01.199

Franchini, E., Panissa, V. L. G., \& Julio, U. F. (2013). Physiological and Performance Responses to Intermittent Uchi-komi in Judo. Journal of Strength and Conditioning Research, 27(4), 11471155. doi: 10.1519/ISC.0b013e3182606d27

Kamandulis, S., Bruzas, V., Mockus, P., Stasiulis, A., Snieckus, A., \& Venckunas, T. (2018). Sportspecific repeated sprint training improves punching ability and upper-body aerobic power in experienced amateur boxers. Journal of Strength and Conditioning Research, 32(5), 12141221. doi: $10.1519 /$ ISC.0000000000002056

Ravier, G., Dugué, B., Grappe, F., \& Rouillon, J. D. (2009). Impressive anaerobic adaptations in elite karate athletes due to few intensive intermittent sessions added to regular karate training. Scandinavian Journal of Medicine and Science in Sports, 19(5), 687-694. doi: 10.1111/i.16000838.2008.00807.x

Ribeiro, R., Oliveira Silva, J. Í., Dantas, M. G. B., Menezes, E. S., Pereira Arruda, A. C., \& Schwingel, P. A. (2015). High-intensity interval training applied in Brazilian Jiu-jitsu is more effective to improve athletic performance and body composition. Journal of Combat Sports and Martial Arts, 6(1), 1-5. doi: 10.5604/20815735.1166073

Salles, P. de, Vasconcellos, F., de Salles, G., Fonseca, R., \& Dantas, E. (2012). Validity and Reproducibility of the Sargent Jump Test in the Assessment of Explosive Strength in Soccer Players. Journal of Human Kinetics, 33(1), 115-121. doi: 10.2478/v10078-012-0050-4

Silva, J. J. R., Del Vecchio, F. B., Picanço, L. M., Takito, M. Y., \& Franchini, E. (2011). Time-motion analysis in Muay-Thai and Kick-Boxing amateur matches. Journal of Human Sport and Exercise, 6(3), 490-496. doi: 10.4100/jhse.2011.63.02

Theeboom, M., Zhu, D., \& Vertonghen, J. (2017). 'Wushu belongs to the world'. But the gold goes to China...: The international development of the Chinese martial arts. International Review for the Sociology of Sport. doi: $10.1177 / 1012690215581605$

Vasconcelos, B. B., \& Del Vecchio, F. B. (2017). Wushu Sanda: Color bias, home advantage and motor actions analysis in female matches' from the 13th World Championships. Revista de Artes Marciales Asiáticas, 12(1), 1-9. doi: 10.18002/rama.v12i1.4858

Yin, H. (2010). An analysis of technique and tactics characteristics of men's Sanshou final in the 11th National Game. Journal of Beijing Sport University, 33(6), 139-142.

Yoshida, H. M., \& Ribeiro, S. (2016). Artigo De Revisão Wushu E Aspectos Do Treinamento. Caderno de Educação Física e Esporte, 14(1), 69-78.

\section{Author's biographical data}

Jorge Rafael Farias Monteiro (Brazil). Graduated in Physical Education - (UFPA). Brown belt and instructor of wushu sanda. E-mail: rafaelfariasrnr35@gmail.com

Fabrício Boscolo Del Vecchio (Brazil). PhD researcher at the Federal University of Pelotas. Fabrício is the leader of the Group of studies in physical fitness and sports performance, and have relevant experience and contribution to combat sports science. E-mail: fabricio boscolo@gmail.com 
Breno Berny Vasconcelos (Brazil). Master degree student. Currently he is focused in wushu research. Email: brenobvasc@gmail.com

Victor Silveira Coswig (Brazil). PhD researcher at the Federal University of Pará. Victor coordinates the Laboratory of Combat Sports Applied Physiology and have relevant experience and contribution to combat sports science. E-mail: vcoswig@gmail.com 